\title{
Os Xerente: estrutura, história e política
}

\author{
Ivo Schroeder \\ Doutor em Antropologia Social (USP-São Paulo) \\ São Paulo, SP, Brasil \\ ivo.sc@terra.com.br
}

\begin{abstract}
Resumo O campo da política entre os Xerente dialoga com sua estrutura social e aqui é abordado a partir de sua distribuição espacial em dezenas de aldeias relativamente autônomas. A fundação de aldeias replica e fortalece uma estrutura social que opera por oposições entre lados ou turmas. Uma sociedade assim fragmentada, contudo, é capaz de ações concertadas na defesa de interesses coletivos. A não ser nesses eventos fugazes, porém, os interesses dos grupamentos se impõem e a representação política é suspeita. A memória social, povoada pelas histórias da má escolha, quando jogaram fora as novidades dos brancos, se vê mobilizada para uma aproximação das políticas públicas e da forma de fazer política do branco, em que de novo eles se apresentam em turmas, pois esta é a forma própria de ser Akwẽ Ktabi.
\end{abstract}

Palavras-chave: índios Xerente, história e memória social, aldeamento Theresa Christina, sociedades dualistas, estrutura social e política indígena.

\section{Introdução}

$\mathrm{O}$

s Xerente, junto com os Xavante e Xakriabá, são classificados como Jê Centrais e se localizam no município de Tocantínia (TO), cerca de $70 \mathrm{~km}$ ao norte da capital, Palmas, entre os rios Tocantins e do Sono, nas terras indígenas Xerente e Funil, que somam 183.245,902 hectares.

No Censo realizado em 1999, ${ }^{1}$ a população xerente era de 1.850 indivíduos, distribuídos em 34 aldeias e nas cidades de Tocantínia e Miracema do Tocantins. As maiores eram então Porteira (167), Salto (158), Funil (186), Rio do Sono (104) e Brejo Comprido (80), mas a maioria contava com contingentes de 30 a 40 pessoas. Nas cidades de Tocantínia e Miracema, eram 98 e 6 moradores respectivamente, mas esta população estava subestimada; ela cresceu a olhos vistos, sendo Tocantínia hoje seguramente a maior "aldeia", entre estudantes, aposentados e funcionários das duas associações indígenas e de dois programas de assistência ao povo Xerente. No período de minha pesquisa, nos anos de 2003 e 2004, a Associação Indígena Xerente (AIX) estava conveniada com a Funasa, para prestar assistência à saúde, e a Associação Indígena Akwẽ (AIA) tinha convênio com a Funai para a contratação das pessoas que atuavam no âmbito do Programa de Compensação Ambiental Xerente (Procambix), em execução desde 2001. Quanto aos estudantes, consta que em 2004 eram 221 alunos, na $5^{\text {a a }} 8^{a}$ séries e no ensino médio, nas duas cidades, muitos deles residindo na cidade.

Os Xerente se apresentam em duas metades exogâmicas, cindindo a sociedade entre nós e eles. De um lado, estão os Isake (sdakrã ou

1 Diagnóstico etnoambiental das terras indígenas Xerente e Funil, realizado pela Opan e Gera/UFMT. Era uma das exigências dos órgãos licenciadores da hidrelétrica Lajeado, em construção no rio Tocantins, $10 \mathrm{~km}$ a montante das terras xerente, e tinha como fim a elaboração de um programa de gestão territorial. 
wairi) e, de outro, os Dohi (siptato ou doi). Do lado Isake, citam-se os clãs wahire, krozake e krãiprehi e, do lado Dohi, os clãs kuzâ, kbazi e krito. Nas pinturas corporais, os primeiros usam como motivo o traço e os últimos, o círculo. Além da exogamia, essa estrutura comanda a vida ritual, na qual clãs confrontantes que se tratam por daziwasé devem trabalhar juntos, tal como na nominação feminina; ou ainda realizar o enterro e o ritual do kupre, um lado para o outro. $\mathrm{Na}$ política novamente comparecem as metades e os clãs, obrigando ao respeito e ao apaziguamento nos conflitos de um lado pelo outro.

Pretendo confrontar as fontes dos séculos XVIII e XIX com eventos alcançados pela memória, tal como o trabalho dos freis capuchinhos, a partir de meados do século XIX, e as viagens ao Rio de Janeiro e a São Paulo, no final do Império e nos primórdios da República. Para o século XX, existem relatos mais precisos sobre a localização de aldeias, a distribuição da população e a relação com o território atual; todas são variáveis que interagem com a estrutura das turmas e das metades, formando o substrato do campo político.

\section{Os Xerente e os Xavante em Goiás}

Aracy Lopes da Silva afirma que datam do século XVIII, ao se intensificarem as Bandeiras em busca de jazidas de ouro na região do Tocantins e do Araguaia, as primeiras referências documentais acerca de grupos Xerente e Xavante. A resistência que estes e outros povos ofereceram à invasão de seus territórios suscitaria reações do poder público e dos colonizadores, alternando-se guerras de extermínio, aldeamentos e proselitismo missionário (Lopes da Silva, 1992, p. 364).

Agenor Farias (1994) assinala os esforços para aldear os grupos tribais, fundando-se, entre outros, os aldeamentos de São José, para os índios Acroá da aldeia do Duro, em 1775; Carretão ou Pedro III, em 1784, para os Xavante; Salinas ou Boa Vista, em 1788, para os Xavante e Javaé que saíram de Carretão, e a aldeia S. Francisco Xavier, para os índios Xakriabá e Acroá.

O Marquês de Pombal, em 1755, impusera uma política de integração dos índios, através dos aldeamentos, sob a direção de diretores leigos, em lugar dos jesuítas, expulsos em 1759. Segundo Mary Karasch, após as reformas de Pombal, os índios resistiram ao trabalho escravo, fugiram e começaram a atacar as fazendas e cidades mineiras. Punições foram autorizadas e, em 1784, foi fundado o aldeamento do Carretão, após a guerra movida contra os Akroá, Xakriabá e Xavante, pelo governador Tristão da Cunha Menezes (1992, p. 398).

Os Xerente habitavam as caatingas do médio Tocantins, entre os rios Manuel Alves Grande e Manuel
Alves Pequeno e nos sertões do Duro, quando foram submetidos, em 1810, por Fernando Delgado Freire de Castilho, que governou Goiás de 1809 a 1820 (Alencastre, 1964-1965, apud Magalhães, 1928, p. 8). Para o ano de 1812, o padre Luiz Antônio da Silva e Souza anotou que os Xerente são uma "nação que existe acima da cachoeira de Lageado, no Tocantins, e se estende até os sertões do Duro, entre o Rio Preto e Maranhão, aonde têm sete aldeias: são valentes e trabalhadores" (apud Magalhães, 1928, p. 6).

A aldeia Graciosa foi estabelecida para os Xerente pelo brigadeiro Raymundo J. da Cunha Mattos em 1824, no rio Taquaruçu, junto à confluência com o Tocantins, no sítio Barreira Vermelha, após a celebração de um pacto que exigia dos Xerente o seguinte: deveriam obedecer ao governo e defendê-lo; não fariam guerra ofensiva; abandonariam o costume de se vender como escravos; receberiam a santa religião, e adotariam os costumes dos civilizados (Brasil, 1924, p. 202).

A política de aldeamentos, no entanto, fracassou em consequência da má administração, dos maus tratos infligidos aos índios, da falta de clérigos e de seu desentendimento com as administrações militares. Mesmo assim, a Carta Régia de 5/9/1811 reitera a necessidade de pacificação e autoriza a guerra aos grupos tribais, citando os Apinajé, os Xavante, os Xerente e os Canoeiros. Farias assinala, então, uma relação defensiva do poder público, através da criação de presídios militares como Santa Maria do Araguaia, que fora construído em 1812 e destruído no ano seguinte por uma federação de índios Xerente, Xavante e Karajá (1994, p. 27-29).

Segundo Karasch, mesmo após a Independência, a política indigenista regional pouco se alterou:

Em Goiás, novos colonos e criadores de gado continuavam a 'desinfestar' a província de seus índios não assimilados, escravizando a quantos podiam [...]. Os índios ficavam sujeitos aos novos invasores, fugiam pelo Araguaia para refugiar-se a oeste do rio, ou então morriam nas violentas guerras do período. $\mathrm{O}$ fato de tantos terem sobrevivido aos longos anos de domínio luso-brasileiro em Goiás é prova da força das estruturas sociopolíticas indígenas, que permitiram a alguns resistir a guerras, conquista e escravização. (Karasch, 1992, p. 397)

Sobre o cisma entre os Xavante e os Xerente, no século XIX, os dois povos são citados lado a lado, alguns apresentando-os como tribos aliadas (Alencastre, 1865 , p. 92-97) ou como a mesma tribo, mas quando foram amansados os dissidentes deixaram a região do rio do Sono (Coudreau, 1897, p. 211). Ou, ainda, os Xerente e os Akroá, "subjugados" pelos Xavante, "misturaram-se com a tribo vencedora, for- 
mando um todo" (Pohl, 1951, p. 132). Para Urbino Vianna, "o gentio Akuen ou Xerente [...] pertence à mesma e grande divisão tribal dos Xavante, sem, comtudo com elle confundir-se" (1928, p. 33).

Oswaldo M. Ravagnani, ao confrontar seus dados com esses e outros autores, propõe que "Xerente e Xavante são subdivisões de um único grupo que no início do século XIX formavam dois grupos distintos, mas culturalmente muito próximos". O autor insiste que o cisma foi anterior à separação - os dois povos ocupavam aldeias separadas no mesmo território - e que a polarização de opiniões diante dos colonizadores data dos primeiros anos do século XIX, após a fuga do Carretão. Enquanto uma facção procurou o governador para ser aldeada, em 1810, outra atacou o presídio de Santa Maria. Assim, aqueles que se recusavam ao contato se refugiaram ao norte da província e em direção ao rio Araguaia, até transpô-lo. Estes foram chamados de Xavante, descritos como ferozes e bárbaros. Os outros que se mantiveram em seu território, favoráveis ao convívio e desejosos do contato com os civilizados, foram chamados de Xerente (1991, p. 64-67).

\section{Aldeamento Theresa Christina}

Foi em 1851 que o capuchinho italiano frei Rafael de Taggia fundou Theresa Christina (depois Piabanha; hoje Tocantínia) e ali reuniu 2.139 Xerente e Xavante, conforme o censo que fez. Tal número é "aproximativo, sendo quase impossível offerecer uma relação exacta, pois em nenhum tempo acham-se juntos" (Taggia, 1898, p. 119-120).

Acrescenta frei Taggia que estes povos foram "muito dizimados pelas epidemias frequentes, e nas invasões das Bandeiras; porém, como são muito prolíficos, e continuando a viver em paz, ficaram vistosamente aumentados". Recomenda assim que o governo providencie o sustento deles, "tanto mais que os produtos de casa vão ficando diminuídos" (Taggia, 1898, p. 120).

A respeito da aldeia de Piabanha, Karasch resume:

As aldeias Piabanhas, Pedro Afonso e Boa Vista ficavam na região do Tocantins. No início da década de 1880, eram administradas por Antonio Fleury Curado. Piabanhas, fundada para 3800 Xerente e Xavante em 1851, ainda era uma aldeia relativamente bem-sucedida em 1880. Em 1852, frei Rafael de Taggia registrou 2139 Xavante e Xerente na aldeia, que em 1874 abrigava 3 mil Xerente e Krahô. Seis anos de- pois, apenas 2 mil Xavante e Xerente eram contados em Piabanhas, habitando 220 casas cobertas de palha, e vivendo da pesca, agricultura e navegação fluvial. A aldeia tinha uma escola primária com 31 crianças, uma capela e um missionário residente, frei Antonio de Gange. Em 1886 apenas cem lares restavam, com 1500 'almas', das quais quase a metade (setecentas) tinha sido batizada em 1882. No final do século, restavam algumas centenas de Xerente; todos os Xavante estavam 'extintos'. (1992, p. 408)

\section{Memória social e história}

Em meados do século XIX, ao norte da cachoeira Funil, em ambas as margens do rio Tocantins, confrontando ao norte com os Krahô, nos encontramos em território dos Akwẽ Xerente. Eles viveram a experiência de Thereza Christina. Data desse período a memória sobre episódios protagonizados pelos Xerente e que lançam luz sobre sua realidade atual. São eventos ligados à sua civilização, quando se veem diante do dilema entre jogar ou aceitar as coisas do branco.

Curt Nimuendaju esteve com os Xerente na década de 1930 e anotou: "de todas as tribos que conheci, os Xerente são os únicos com algum senso de solidariedade racial, transcendendo diferenças linguísticas e guerras tribais. O deus Sol, Waptokwá, é o pai de todos os índios" (1942, p. 9). Ele traduz Cherente por akwe kutabi (1929, p. 28), expressão que usam atualmente para enfatizar que alguém é Xerente puro ou verdadeiro.

Uma versão da sua origem indica como local o Morro Perdido, próximo ao rio Araguaia. De acordo com Sõware, os membros do clã Krito foram os últimos a escolher sua pintura, quando todos já haviam se pintado. Ele esclarece:

Foi do Morro Perdido onde se dividiram, Xavante, Xerente. Karajá foi bem daí do Morro Perdido que foi para o Araguaia. Assim foi toda a nação, tava tudo ali no Morro Perdido. Foi ali que dividiram, Krahô, outras nações, tudo. Então é toda a nação, mas quem ficou em Morro Perdido foi os Xerente e ainda hoje está perto. (Dezembro, 2003)

Nimuendaju apresenta os clãs Krito e Krozake como tribos incorporadas, que originalmente moravam nas montanhas do divisor de águas do Araguaia e do Tocantins (1942, p. 19).

O nome masculino Hêsukamẽkwa ${ }^{2}$ parece estar ligado à chegada da missão. Segundo Gabriel Romkrã, 
teria sido um papel que o missionário prendera num pau e que foi achado por um tal Zé da Mata, provavelmente um regional que já sabia ler. No papel estava escrito que o padre vai descendo [para Carolina-MA] e queria saber se um índio poderia acompanhá-lo. Zé da Mata chamou os mais velhos e, por causa do papel, colocaram-lhe o nome de Hêsukamẽkwa e foram com ele até os Krahó, onde estava o padre. Zé da Mata entrou lá, conversou com o padre, retornou com carne, rapadura e ferramenta e os distribuiu para os Xerente. O pessoal, porém, jogou rapadura, jogou carne, jogou ferramenta. "Retornaram sem nada, somente Zé da Mata trouxe as coisas, mas depois foi ensinando aos Xerente como trabalhar", completa Romkrã.

As narrativas xerente dão conta de que os antigos andavam muito, chegando até Minas Gerais, à Bahia e ao Rio de Janeiro, em viagens que duravam meses e anos, às vezes. Nos anos de 1930, os Xerente tinham uma lembrança viva de dom Pedro II, a quem chamavam de Sliemtõi. Nimuendaju esclarece que:

A pedido especial um nome pode ser conferido a um membro duma divisão que não pode legitimamente reclamá-lo. Entre este é exclusivo para o nome Sliemtõi (-zauré), que é reservado para um homem do clã kuzé. Ele está cotado como o maior dos nomes, tendo segundo os Xerente pertencido ao Imperador Dom Pedro II que reinou entre 1831-1889 e ainda vive em sua memória como a encarnação da benevolência e sabedoria. (1942, p. 45)

James W. Wells, durante sua viagem do Rio de Janeiro ao Maranhão no final do século XIX, desceu o rio do Sono e passou em Pedro Afonso, fundada em 1848 para os Krahó. Sobre os Xerente de Piabanha, relata que, em 1870, o chefe dos Xerente, capitão Gabrielle, junto com um pequeno grupo fez uma longa excursão ao Rio de Janeiro, para visitar o imperador. Eles teriam voltado satisfeitos com sua visita e carregados de presentes (Wells, 1886, p. 219).

José Feliciano de Oliveira relata que alguns Xerente visitaram-no em São Paulo nos anos de 1896 e 1911 e que, em conversações com eles, obteve os dados etnográficos e linguísticos que publicou em vários artigos. Ele próprio se empenhou em subscrições para instrumentos agrícolas e animais e para o envio de uma professora que "entre os Cherentes iria ensinar os rudimentos da vida civilizada" (Oliveira, 1915, p. 13). Urbino Vianna cita o trabalho da

Professora bahiana, d. Leolina Daltro de Figueiredo, domiciliada no Rio de Janeiro, que, em 1899, se transportou a estes sertões da Piabanha, alli abrindo escola de instrucção primaria; levando depois, no seu retorno á capital, alguns índios a que ministrou ensino de leitura, escripta e trabalhos manuaes domesticos. Um destes foi, posteriormente, o professor Djalma (Uakmonp'té), fallecido em 1921, que, na aldeia Sacrêprá, manteve escola, ensinando a irmãos seus da selva. (Vianna, 1928, p. 37)

A atuação indigenista (e feminista) da professora Leolinda é retratada por Mariza Corrêa (2003). Segundo a autora, em 1896, cinco índios Xerente vieram ao Rio de Janeiro para pedir ao presidente fazendas, ferramentas e armas e fizeram uma visita ao jornal O Paiz. Eram eles: Joaquim Sepé Brasil, chefe da aldeia Providência, na Piabanha; Domingos Dabaquerô; Sebastião Dabenharim; Marcelino Decapsicuá, e Bernardo Cumennancé. O jornal registra o seguinte depoimento de Sepé:

Eu faço o que posso... vou buscar bugre no matto, com geito trago elle para o aldeiamento, trato elle bem, elle depois vae contar a outros e outros vem. Mas eu não sei nada, não sei escrever, não posso ensinar os pequenos que vão nascendo, me dóe o coração de ver tanta gente sem ser aproveitada. (Apud Corrêa, 2003, p. 112)

Os Xerente conseguiram falar com o presidente Prudente de Moraes, mas, por falta de verbas, não foram atendidos em suas reivindicações. A professora Leolinda entra em cena e, sempre ladeada pelos índios, prepara sua viagem ao Brasil Central. Em São Paulo, ela consegue apoio de particulares, entre eles o americano Horace Lane, diretor do Colégio Mackenzie, enquanto uma polêmica se instala na imprensa, seja sobre a assistência aos índios, seja sobre o gesto arrojado da professora. Pelo caminho, apoio e oposição se mesclam nas cidades por onde passam a comitiva xerente e a sra. Leolinda. ${ }^{3}$ Em São Sebastião da Piabanha, um distrito de Porto Nacional (GO), em maio de 1898, uma comitiva de 18 índios graduados, acompanhados de 100 a 200 índios de suas respectivas aldeias, teria pedido ao juiz para lavrar um termo de declaração afirmando que desejavam ter Leolinda como sua diretora. Instalou-se assim uma acirrada disputa com o diretor dos índios de Piabanha, frei Antonio de Ganges, que, tudo indica, tornou-se um inimigo velado da professora; consta ainda que o frei teria seduzido um grupo de índios para emboscá-la e que ela conseguiu escapar com vida, tendo a ajuda do chefe Sepé e de um cearense (Corrêa, 2003, p. 123).

Não vi entre os Xerente referências aos fatos relacionados com as desventuras dessa professora, a não ser algumas das fotos do livro de Leolinda, expostas 
na enfermaria da aldeia Porteira. Para eles, o trabalho de frei Antonio continua como uma referência importante. O cacique Simnãkru lembra que, primeiramente, foi Rafael de Taggia quem fundou Pedro Afonso para os Krahó. Os Xerente foram lá e gostaram, e eles próprios teriam ido ao Rio de Janeiro, quando trouxeram o padre Antonio nas costas, para fundar Thereza Christina. Essa versão não vi documentada, mas lembra a forma como, anos mais tarde, uma comitiva indígena esteve realmente no $\mathrm{R}$ io de Janeiro e retornou trazendo a professora Leolinda.

O padre Estevão Gallais (1942, p. 129-140), ao relatar os conflitos dos Xerente com os cristãos que se apoderavam das suas terras, em meados do século XIX, informa que a questão teria sido levada ao tribunal do imperador, que se pronunciou no sentido de um acordo com os Xerente e lhes entregou uma vasta extensão de terras. De acordo com Darcy Ribeiro, o título então concedido garantiu ao imperador um lugar como ancestral mítico de uma das metades tribais (1982, p. 66-67).

Alguns Xerente atribuem ao padre Antonio o mapa de uma grande área etnoambiental reservada, segundo depoimentos sobre seu território atual, recolhidos durante o Diagnóstico etnoambiental: ${ }^{4}$

Desde quando o Xerente existia, já existiu em Morro Grande, Araguaína. Foram tocados para cá. Deu malária, deu sarampo. As aldeias eram grandes, foram se acabando. O padre [Antônio de Ganges] deixou esse quadrado grande. Depois os fazendeiros invadiram. Se tiver uma pessoa que pensa no futuro, vê que não vai dar. Está no mapa do Curt de 1930; a aldeia Esgoto ficou de fora. Se deixasse, o Funil também ficava fora.

O diretor do Idago [da comissão de demarcação] disse que podia cortar onde quisesse. Os velhos não sabiam. Todo mundo sabe que Tocantínia era aldeia. Primeiro, Lajeado, rio do Sono. Tinha o Paneiro, do outro lado do rio do Sono, e o ribeirão Perdida. Os mais novos [precisam], a família está aumentando. (Simnãkru, aldeia Vão Grande)

Nossa área era grande. O branco foi chegando perto. Agora estamos espremidos. Nossa população está crescendo. E os que vêm atrás de nós, nossas criança? A área foi delimitada sob pressão, meu avô e minha avó até apanharam. Nós perdemos o trecho de Lajeado e o Pau Ferrado. No caso do Funil, eles perderam a Passagem de Pedra. Ficou para o branco. Aqui o limite era o rio Negro e a cabeceira das Porcas [cabeceira do Piabanha]; dali era para encostar no Miramata. O limite era por aí. O Xerente perdeu as duas cabeceiras. Os mais velhos pensaram que não ia produzir mais, o índio estava sem esperança. Hoje o número do índio cresceu, depois que passou pela Funai. Surgiu vacina, chegou o leite, remédio, enfermeiro. Essa parte da reserva que a gente perdeu, quem sabe, não vai passar para as mãos dos Xerente, nossos filhos, nossos bisnetos. (Manoel Sukẽ)

Um mapa que se perdeu, os velhos que não sabiam. Sem esperança, pensavam que não iam produzir mais. A par das estórias de perdas e da má escolha que permeiam a memória xerente, uma crítica velada aos antigos que não pensaram no futuro. Raimundo Vicente Ktâpomẽkwa diz que os brancos estão pegando dinheiro e eles nada, que os Xerente vão se acabar, sem ter nada; que Deus deixou, subiu, foi falando "vocês ainda vai precisar; quando matar gado, vocês comem bucho ou é cabeça, fígado”. Ele conta:

De primeiro, tinha muito porco-queixada. Deus primeiro botou foi dinheiro, tocou borá. ${ }^{5}$ Aí Xerente chegou "o que foi, tocando borá?" Deus falou "se vocês quer, podem pegar". "Ah não, para que você está tocando borá, eu pensava que era porco." Agora botou a espingarda, tudo bonito e toca borá. Os Xerente chegam "o que foi?" "Vocês reparem aí, se alguém quiser pegar, pega”, Deus falou. "Ah não, ninguém não pega não, isso aí faz medo, às vezes vai matar um, isso aqui não. Arco que é arma do índio.” Depois foi gado, animal, Deus foi tocando borá de novo. Vem correndo, chega um bocado, "que foi que viu, onde é que está o porco?” Não, tocando borá para isto aí. "Ah, para que você está tocando borá? nós não quer não." Abaixou a cabeça, não quis o gado. Fizeram um barraco, botaram tudo no barraco e ali mesmo deixou os gado tudo. Aí os brancos tomou conta dos gado. Hoje cada um de nós quer. Cadê dinheiro para poder comprar? Não tem. Deus falou "vocês se acabam sem ter nada, quem vai ter é os brancos, agora". Deus era para deixar, mas nós não queria, não pegamos nada. Hoje compra cabeça, pé, como Deus falou. (Ktâpomẽkwa, maio de 2003)

Uma versão desta narrativa foi contada pelo jovem Edivaldo, gerente da Coordenação de Cultura, na $1^{\text {a }}$ Oficina de Avaliação do Procambix, em setembro de 2003, quando os caciques presentes pleiteavam a criação de gado em suas aldeias. O Procambix não previa criação de gado, em razão de tentativas precedentes frustradas, quando o gado foi destinado ao consumo, ao pagamento de débitos ou à resolução de conflitos e, assim, o rebanho foi definhando até acabar. A má escolha primordial continua, dessa forma,

4 Relatório da área de Antropologia. Diagnóstico etnoambiental. 2000, p. 68.

5 Som produzido pelas mãos em cuia. 
a afligir os Xerente em suas novas escolhas, divididos entre jogar ou aceitar as novidades do branco.

Assim, os deslocamentos sucessivos são percebidos pela memória social como um movimento no sentido sul-norte, deixando para trás Graciosa, onde hoje se encontra a capital do Tocantins. O sentido oeste-leste, desde o rio Araguaia, do Morro Perdido, até a margem direita do rio Tocantins, deixando para trás aldeias como Providência, Panela de Ferro, Pedra Hume, todas citadas por ex-moradores. No sentido leste-oeste, uma referência à Bahia e às aldeias que se encontravam à direita do rio do Sono. Ao lado do sentimento de grande perda, se veem num território acanhado demais para o futuro dos seus filhos e netos. Talvez se perguntem como e quando reverter essa trajetória de assimetria com os brancos e, quem sabe, se aquilo que se perdeu vai voltar para as mãos dos Xerente.

Os Xerente se envolveram num debate nacional, sobre o destino dos índios e sobre a política indigenista, destacando-se a afirmação da catequese leiga, bandeira de Leolinda Daltro. Nesse ponto, os Xerente "saíram bem na foto", suas fotografias estavam estampadas nos jornais e eles passaram uma mensagem inteligível no clima de discussões e disputas, instalado no Centro-Sul, em torno da catequese leiga e da proteção aos índios. Ao buscar ferramentas agrícolas e uma professora, davam um sinal inequívoco de sua capacidade de civilizar-se. Ostentando nomes próprios que ainda hoje adotam, revelam também sua forma peculiar de agenciar a exterioridade, dirigemse com elaborado discurso ao Pai Grande - o imperador e depois o presidente -, esperando provocar um sentimento de compaixão, pois "o coração dói”, segundo Sepé, ao ver seus irmãos sofrendo.

\section{Século XX: aldeias e população}

As primeiras décadas do século XX, no entanto, não reservariam boas notícias para os Xerente. Urbino Vianna ainda localiza 12 aldeias, totalizando 1.364 pessoas. A Tabela 1 resume os dados do autor (Viana, 1928, p. 34-35).

De acordo com Darcy Ribeiro (1982, p. 68), os dados do SPI indicavam 800 pessoas em 1929. Curt Nimuendaju, por sua vez, apresenta um mapa com 9 aldeias que encontrou em 1930, estimando uma população de somente 500 pessoas (1942, p. 106). ${ }^{6}$ Em 1937, porém, eram apenas sete aldeias com não mais de 300 pessoas. Descreve então um quadro desolador, havia "bexiga" por toda parte; na aldeia do Boqueirão, Caetano era o capitão e ele estava doente $(2000$, p. 265).

Um censo do SPI de 1941 aponta 7 aldeias, com um total de 374 habitantes, dos quais somente duas se encontravam na margem esquerda do rio Tocantins, Pedra Hume e Providência. Diante do estado de penúria, houve uma intervenção do SPI, que transferiu para a área atual todos os Xerente, que perderam locais históricos na margem esquerda do Tocantins. Fundou-se, então, o posto Tocantínia, onde hoje se encontra a aldeia Porteira. Srêsazu, morador das margens do rio do Sono e neto de Bruwẽ (cacique da

6 As aldeias Pedra Hume, Sucuriju (Providência), Exgotto, Pedra Preta, Castello, Porteira, Boqueirão, Carro e Paineiras.

Tabela 1 - Aldeamentos e população xerente (primeiras décadas do século XX)

\begin{tabular}{|l|l|c|}
\hline \multicolumn{2}{|l|}{ Aldeamentos } & População \\
\hline 1 & Quitê-crê (Barreiro da Anta na Panela de Ferro, na margem esquerda do Tocantins) & $\mathbf{2 6 0}$ \\
\hline 2 & Cidaran (Varedão, na margem direita do Tocantins) & $\mathbf{2 4 3}$ \\
\hline 3 & Sacrê-prá (Boqueirão do Funil, abaixo do Lageado) & $\mathbf{1 6 3}$ \\
\hline 4 & Spró-rrhû (Bananal, no rio Preto, esquerda do rio Sono) & $\mathbf{1 4 6}$ \\
\hline 5 & M'ran-rópé (Mato Limpo, na Prata, rib. Cachoeira, à esquerda do Tocantins) & $\mathbf{1 4 2}$ \\
\hline 6 & Brûnû-caré (Rocinha, no rib. dos Bois, esquerda do Tocantins) & $\mathbf{1 1 2}$ \\
\hline 7 & Nhoron-tó-udê rrhû (Anajazal, em Morrinhos, cabeceira do Piabanhas) & $\mathbf{1 0 0}$ \\
\hline 8 & Nhoron-ró-zauréd (Cocal) & $\mathbf{5 0}$ \\
\hline 9 & Zé-zauréd (Barra Larga, no Gorgulho, rib. dos Bois, à esquerda do Tocantins) & $\mathbf{4 9}$ \\
\hline 10 & Nhoron-zauréd (Coqueiro Alto, em S. João, à esquerda do Tocantins, defronte a Pedro Afonso) & $\mathbf{4 1}$ \\
\hline 11 & Zueré-quêrizé (no Morro Grande, na fralda da Cordilheira, mudou para Garrafas) & $\mathbf{3 8}$ \\
\hline 12 & Nhoron-ró-quê-rrhû (Palmeira, na Providência) & $\mathbf{1 6}$ \\
\hline & & $\mathbf{1 . 3 6 0}$ \\
\hline
\end{tabular}


aldeia Providência e informante de Nimuendaju em 1937), relatou que a transferência "foi no tempo da revolução nos Krahó. ${ }^{7}$ Arrastaram tudo, não deixou os Xerente para lá” (Srêsazu, julho, 2004).

A intervenção do SPI, porém, não parece ter alterado a sorte dos Xerente. Com efeito, 15 anos mais tarde, Maybury-Lewis (1990) relata um quadro continuado de penúria, falta de assistência, conflitos com criadores de gado, as suas terras cercadas e se reduzindo. O pesquisador se hospedou com o cacique Jacinto, na aldeia Gorgulho. Os seus informantes reivindicavam sua terra de volta, indicando limites antigos que incluíam uma aldeia conhecida por $\mathrm{Pa}$ nela de Ferro. Quanto aos colonos, eles estavam em estado de perpétua indignação com os Xerente, e estes se queixavam de estar sendo expulsos de Tocantínia. Para o ano de 1963, Maybury-Lewis assinala 8 aldeias, estimando-os em 500 pessoas (1979, p. 221).

\section{Demarcação das TI Xerente e Funil}

Entre as décadas de 1930 e 60, o povo Xerente viveu talvez sua pior crise. Toda a população foi concentrada no território entre os rios Tocantins e do Sono, não passavam de 400 pessoas. Grande parte da área estava então tomada por dezenas de criadores de gado, a tal ponto que o SPI, em 1953, chegou a propor a demarcação de três áreas descontínuas, uma maior no rio do Sono, onde havia um posto do órgão, outra em torno do posto Tocantínia, que incluía as aldeias Gorgulho, Porteira e Baixão, e uma última para a aldeia Boqueirão.

Em 1944, a Inspetoria do SPI em Goiás tratou de requerer ao interventor do Estado, Pedro Ludovico Teixeira, uma área calculada em 174 mil hectares, limitada ao norte pelo ribeirão Gorgulho, a leste pelo rio do Sono, ao sul pelo rio Preto e ribeirão Piabanha e a oeste pelo rio Tocantins. Em 1953 o chefe da Inspetoria, porém, propôs que se reservasse algumas áreas descontínuas, uma maior a partir do rio do Sono, que serviria para atrair os Xerente, e outras menores, em torno das aldeias Baixão, Porteira e Boqueirão e do posto Tocantínia. À época, cerca de dezessete fazendas, algumas demarcadas com autorização de órgãos estaduais, dividiam aquelas terras e pressionavam as aldeias Xerente. Tal situação levou o SPI, em 1963, a ingressar em juízo com uma ação de manutenção de posse - então, já habitavam a área setenta e cinco famílias de sitiantes, a maior parte com titulações obtidas há pouco tempo (Arquivos do SPI/
Museu do Índio). Na região do rio Preto, por exemplo, os lotes foram alienados pelo governo estadual no ano de 1962. (Opan, 2000, p. 64)

A situação atingiu seu clímax no ano de 1971, quando os Xerente saquearam diversas fazendas e exigiram que os fazendeiros se retirassem daquelas terras. Em represália, o xerente Salu foi baleado na aldeia Funil pelo fazendeiro Judiá Pinto, revoltado com a perda de várias reses (Correio do Povo, 3 e 4, set. 1971).

Esse clima de conflagração motivou a formação de uma comissão mista, com representantes da Funai e do governo do Estado, com o objetivo de estudar uma proposta de demarcação da área indígena. Pressionado pelas autoridades locais, sob o argumento de que a área pretendida alcançaria $80 \%$ do território do município, inviabilizando-o economicamente, o grupo de trabalho então constituído pelas Portarias 60/E/71 e 80/E/72 afinal concordou com a redução da área reservada para 167.542 hectares. A área Xerente foi então delimitada pelo Decreto 71.107, de 14 de junho de 1972, e demarcada em 1974, sem que se procedesse, entretanto, à sua desocupação.

Em 6 de julho de 1976, um conflito resultou na morte de três pessoas. A terra estava demarcada, mas os moradores posseiros continuavam na área à espera de indenização. Os Xerente começaram a abrir uma roça na região do Baixão. Estavam acampados ali, realizando o serviço, quando, ao amanhecer, chegaram, numa camionete C-10, Deusdete Carneiro, exvereador; seu irmão, o tenente Antonio F. Carneiro, da polícia de São Paulo; Cândido, peão dos Carneiro, e o vaqueiro de nome Cristino. No confronto, morreram os irmãos Carneiro e Cândido, enquanto o vaqueiro Cristino fugiu. Do lado dos índios, Marcelino teve um olho vazado por um tiro e João Srênoku foi alvo de vários disparos. Segundo um jornal da época, detonado o tiro que perfurou o olho de João Srênoku, "os Xerente logo se armaram com os pedaços de pau que iam sendo encontrados nas imediações e enfrentaram seus agressores, matando três deles". O mesmo jornal ainda informa que a Polícia Federal apreendeu "no local da agressão - dentro dos limites do PI Xerentes - as armas deixadas pelos brancos; além de dois revólveres, um mosquetão (privativo das Forças Armadas) e sua munição". Os dois Xerente gravemente feridos ainda moravam no PI Xerente em 2004.

Quanto à área do Funil, as lideranças dali solicitavam a demarcação de 32.400 hectares. No entanto, o delegado da Funai, Ivan Baiocchi, efetuou gestões, afinal infrutíferas, para a remoção dos cerca de se- 
tenta moradores e chegou a lhes oferecer um projeto agrícola de médio porte, a ser implantado dentro da reserva já demarcada. Somente em 1979, quando outra vez acirraram-se as hostilidades e os protestos dos munícipes, a Funai constituiu um novo grupo de trabalho, através da Portaria 644/E, de 13/11/79, que concordou com uma área de apenas 15.703 hectares, demarcada em 1991.

A retirada dos invasores da área demarcada só se completaria em 1983, promovida pelos próprios Xerente, com a ajuda de índios Xavante e o apoio dos chefes de posto da Funai. Com a área desimpedida, os Xerente encetaram um movimento de retorno, reocupando vários sítios e locais de antigas aldeias e criando novos assentamentos. As segmentações recentes envolveram os três postos indígenas (Xerente, PI Funil e Rio do Sono) e resultaram na fundação de mais dois postos - Mirassol (Brupre) e Brejo Comprido -, somando ao todo 34 aldeias em 1999, que já alcançavam mais de 40 em 2004 e, em 2008, se falava em 56 aldeias.

\section{Política entre os Xerente}

Retratei como eles foram confinados no território atual, quando os fatos e a memória evidenciam sua interação ativa com as frentes de expansão. A sua distribuição espacial é função do modo de ser da estrutura social, quando comparecem clãs e linhagens, relações de parentesco e a interação com a estrutura administrativa do SPI e da Funai.

Na publicação dos resultados do HCBP (1979), percebe-se que os Jê Centrais destoam de um modelo Jê: eles têm clãs patrilineares, e os Xerente contam com metades exogâmicas. Quanto à política, ao contrário dos Jê Setentrionais, ela não estaria confinada aos segmentos residenciais na periferia, mas no centro do sistema, uma vez que as linhagens Xavante e os clãs Xerente constituem o suporte principal para a composição dos grupos políticos. A política assim tende a ocupar o centro do sistema, pois as disputas políticas são aquelas que envolvem os caciques e as turmas, os clãs e seus anciãos, transbordando muitas vezes para as instâncias governamentais e envolvendo funcionários e autoridades.

O pesquisador David Maybury-Lewis, nos anos 50, observou que as turmas em disputa eram extraídas dos clãs, por isso o sistema clânico seria a instituição mais vital, uma vez que determinava o recrutamento para as facções que dominavam a vida social. No plano interno, as aldeias estariam fundadas numa relação de oposição entre duas facções clânicas principais, sendo dominante aquela à qual pertencia o chefe (1979, p. 223). Farias (1990) também sustenta que as aldeias se apresentam com duas facções em disputa, e o lado perdedor se retira e funda uma nova aldeia. Isso, segundo ele, resultou em três conjuntos de aldeias ${ }^{8}$ internamente cindidos. Partilhando, porém, uma história recente em comum, as aldeias de cada conjunto continuam a realizar entre si os principais rituais, recompondo dessa forma a totalidade da sociedade que se cindiu.

Para Luiz Roberto De Paula (2000), os Xerente fazem política no campo das esferas local e regional. As facções, porém, não repousam sobre os clãs, na análise do autor, mas enfeixam conjuntos de aldeias que se opõem - De Paula as trata como zonas geopolíticas. Se Farias considerou esses conjuntos como unidades rituais, De Paula (2000) vai conferir-lhes uma unidade faccional. No período de sua pesquisa, as aldeias do PI Xerente estavam alinhadas com a Funai e o CIMI, e as aldeias do PI Brejo Comprido com o governo do Estado, havendo ainda aldeias não alinhadas a nenhum desses agentes externos.

Esses conjuntos então enfatizam uma unidade entre aldeias dispersas que se sentem interligadas por laços históricos, rituais e de cooperação em projetos econômicos. As aldeias de cada conjunto são atendidas por um posto da Funai que, por sua vez, tende a moldar e reforçar a sua unidade, desde que a coordenação dos projetos e o atendimento à saúde sejam centralizados nos postos.

Quanto aos assentamentos, sobretudo as aldeias maiores - algumas hoje com mais de 200 moradores - contam com duas ou mais "turmas" ou "lados" que podem tomar a designação do clã do seu líder. Uma turma buscará a hegemonia, compondo-se com outras para indicar o cacique - o vice-cacique, em regra, deve ser de outra turma. Um grupo descontente pode retirar-se, para formar um novo assentamento. Raramente são retiradas pacíficas, envolvendo momentos de conflitos sérios, de enfrentamentos e ameaças, processos permeados de longas reuniões, gestões de apaziguamento e finalmente a busca de novo local. É nesse deslocamento, enfim, que a estrutura dessas turmas se torna mais nítida.

As aldeias atuais não atendem em geral ao ideal das descrições dos informantes, de conter num semicírculo todos os clãs, cada qual com seu confrontante. Em geral, reúnem várias famílias, que afirmam entre si relações de parentesco e alimentam e reforçam uma lealdade política. O núcleo central de uma aldeia pode ser um pai com seus filhos; um sogro com genros; cunhados e consogros; um grupo de germanos 
e seus afins. Na medida em que as aldeias se consolidam, buscam ter escola, rádio, estrada, poço e água encanada e algumas pessoas contratadas como professores, agentes de saúde e de saneamento. Estes se tornam itens importantes para atestar a capacidade do cacique de agenciar os parceiros externos e consolidar o status de aldeia.

\section{O papel do cacique: apaziguador, provedor, orador}

O papel do cacique é crucial no recrutamento e na condução de sua turma, seja durante o conflito aberto, seja na constituição de uma nova aldeia. Tomando os traços distintivos da chefia, de acordo com Pierre Clastres (1990), teríamos as características de apaziguador profissional, de dever ser generoso e bom orador e, por fim, o privilégio da poliginia ( $p$. 27). Para Clastres, o poder nas sociedades primitivas foi posto fora da sociedade, pois não se encontra no circuito das trocas e da reciprocidade, constituindo uma relação negativa com o grupo e assim ficando desvestido de autoridade (p. 31).

Ao discutir a "estética da corresidência", Peter Gow discorda de Clastres sobre a ideia de troca desigual e afirma que a fala da chefia no baixo Urubamba [no Peru] não é vazia, como estética, pois, segundo o autor, a comunidade nativa só existe através da palavra. A comunidade não é anterior ao chefe, que antes a constitui. Assim, o discurso não somente remete aos valores partilhados, mas também aos elos frágeis que mantêm o grupo unido, lembrando sempre por que as pessoas vivem juntas, apelando a valores estéticos "é bom viver em aldeias, fazer festas; é ruim brigar..." (1991, p. 226-227).

Isso remete à obrigação da fala que se espera dos caciques. Discursar, discernir, aconselhar, reiterar. É assim que os mais velhos tomam a si a responsabilidade de desempenhar ou transmitir a tradição que herdaram dos ancestrais. É bom falar, falar bonito, de forma ritualizada. A fala lembra, propõe, discorda, repete, confirma, cria acordos e consensos. Falar é um dom, é arte, tem um sentido em si. A fala permeia todas as atividades, de um homem se espera que ele fale, pois homens importantes têm de saber falar.

Dos caciques xerente se espera que honrem a tradição, sejam conselheiros, que saibam falar, que cuidem dos interesses de seu grupo. Os caciques, por sua vez, costumam enumerar os obstáculos ao bom governo: uma extensa ordem de dificuldades para conduzir seu povo; a representação em inúmeros foros toma-lhes o tempo e as energias. Tratar das rixas, apaziguar e compor, distribuir tudo de forma equâni- me, proteger quem o indicou, consertar o maquinário, organizar a distribuição de terras para o plantio; organizar o trato e a limpeza das roças, receber e acomodar visitantes, ser hospitaleiro, contornar as fofocas, acudir, agasalhar, combinar, aconselhar-se com os velhos e mobilizar as turmas; receber as delegações de agentes ligados às políticas de assistência. Viagens à cidade, até a capital federal.

Para entender o status de um cacique xerente, ainda nos podemos valer de um estudo comparativo de Marshall Sahlins ([1963]2004) entre as chefaturas políticas da Polinésia e os "grandes-homens" na Melanésia. Estes conquistam seu status e seu poder é pessoal e reconhecido apenas nas relações interpessoais (p. 84). A obra do "grande-homem" é estabelecer lealdades, ampliar o grupo doméstico, agregar outros, para ter maior produção para poder distribuir. Ao distribuir, deve extrair da facção de seguidores, mas a retirada excessiva de excedentes pode levar à deserção e esta é a contradição dessa estrutura, na qual os laços pessoais refreiam o avanço evolutivo da ordem política melanésia. "Os limites e fraquezas da ordem política geral são também os limites e fraquezas dos grupos faccionais que os compõem" (p. 87).

De maneira semelhante, o quadro de atuação dos caciques xerente, cabeças de turmas instáveis, continuamente tem de reconstruir as lealdades a partir de laços pessoais. Nas aldeias onde haja disputas entre turmas, a vigilância sobre o cacique é permanente. Mesmo exercitando um conjunto de virtudes, uma turma poderá vir a pedir sua substituição. $\mathrm{O}$ cacique pode ser acusado de reter as coisas para seu grupo, de não ter habilidade para compor conflitos, de preterir alguém na atribuição de roças ou na distribuição da colheita etc.

Inquirido sobre a força dos caciques, Sõiti argumentou:

Vejo assim: entrei, tinha oito caciques, era mais fácil resolver o problema, tratar na Funai, saía mais resultado que agora com 36 caciques. Para ser cacique tem que ter experiência, tem que ouvir os mais velhos, para poder aprender as coisas.

Raimundo Vicente Ktâpomẽkwa também faz uma avaliação negativa, apontando o despreparo e os interesses pessoais dos caciques novos:

De primeiro não tinha cacique; era só dois capitão. Se tivesse para resolver chamava o Amaro. Depois deste, foi Ademar. Depois ajuntou tudo, tem muito cacique, pro Rio Sono tem é demais. Quando ajunta é muito capitão, tudo já é novo, não sabe levar as coisas, não conhece das coisas...

Antigamente é mais velho, conhece tudo, ajuda para poder contar história, ficar sabendo como é de primeiro. Estes novos não dá nem conselho para criar 
os filhos, tratar mulher, para poder viver. Por isso, é como veado brabo, não dá conselho porque não conhece nada.

Os informantes criticam a proliferação da figura dos caciques, ao que atribuem as dificuldades crescentes na busca de consensos, fragilizando sua força política.

\section{Os Xerente partidos}

Segundo a bibliografia, a união entre todas as aldeias, no passado, ocorria em ocasiões especiais, como as guerras, a realização da festa do grande jejum, a iniciação do Wakedi, a celebração do Kupre para mortos de grande prestígio. A história recente também dá conta de eventos que congregaram a totalidade dos Xerente, com destaque para a demarcação das terras e a campanha para a retirada dos intrusos, nos anos 70 e 80; ou o embargo de estradas e da construção de uma ponte sobre o rio do Sono e a experiência de criação da Associação Indígena Xerente (AIX), nos anos 90. No entanto, as composições supra-aldeãs se encontram limitadas porque se trata da justaposição mecânica de unidades autônomas, cujos interesses divergentes irrompem de forma incontrolada, solapando unidades maiores ad hoc constituídas.

A descrição da esfera política nos leva a crer num processo de fragmentação sem fim. Com efeito, os assentamentos afirmam uma simetria entre unidades, na qual se infiltrou uma assimetria via relações de parentesco, tema que no escopo deste artigo não cabe desenvolver. Se as relações de parentesco impõem uma assimetria entre grupos de afins através do casamento e sendo a regra casar com alguém do outro lado, resulta também que os parentes se distribuem por todas as aldeias. Assim, a fragmentação da política tanto será compensada pela unidade produzida nos rituais, quanto inibida pelas relações entre parentes que se encontram em toda parte.

Persiste o dilema de sempre se apresentarem partidos, uma característica que lança raízes profundas em sua história e em sua estrutura social. Às vezes lhes parece algo a superar, mas o dualismo se replica em tudo o que tocam, também quando interagem com as instituições públicas. Além de se aglutinar em duas associações, cada uma contando com a lealdade de determinado número de aldeias, em 2004 também elegeram dois vereadores, dos clãs wahire e krito; e novamente dois em 2008, ambos do clã krozake, mas de conjuntos distintos. Adicionalmente, esses vereadores indígenas se filiam às aldeias que dão sustentação às duas associações (AIA e AIX) e que de certa forma reproduzem os blocos que cindem a sua estrutura política. Da mesma forma, filiam-se a partidos políticos distintos: respectivamente, $\mathrm{PT}$ e PL em 2004 e PT e PMDB em 2008. Assim, sua estrutura social se replica e se fortalece, nos mais variados campos onde comparecem os Xerente, que persistem como Akwẽ ktabi.

\section{Referências}

ALENCASTRE, José Martins Pereira. Annaes da província de Goyaz. Revista do Instituto Histórico e Geográfico Brasileiro, tomo 27 (parte 2), p. 5-186, tomo 28 (parte 2), p. 5-168, 1864-1865.

BRASIL, Americano. Cunha Mattos em Goyaz, 18231826. Revista do Instituto Histórico e Geográfico Brasileiro, tomo 96, v. 150, 1924.

CHAIM, Marivone M. Aldeamentos indígenas - Goiás 17491811. São Paulo: Nobel. Brasília: INL, 1983.

CLASTRES, Pierre. A sociedade contra o Estado. 5. ed. Rio de Janeiro: Francisco Alves, 1990.

CORRÊA, Mariza. Antropólogas e antropologia. Belo Horizonte: Editora UFMG, 2003.

COUDREAU, Henri. Voyage au Tocantins-Araguaya. Paris: A. Lahure, 1897.

DE PAULA, Luís Roberto. Dinâmica faccional Xerente: esfera local e processos sociopolíticos nacionais e internacionais. 2000. Dissertação (Mestrado em Antropologia) - Universidade de São Paulo, São Paulo, 2000.

FARIAS, Agenor. Fluxos sociais Xerente: organização social e dinâmica das relações entre aldeias. 1990. Dissertação (Mestrado de Antropologia) - Universidade de São Paulo, São Paulo. 1990.

FARIAS, Agenor. Notícia histórica sobre os Akwen-Xerente. Boletim do MPEG, v. 10, n. 1, p. 21-41, 1994. (Série Antropologia).

FERREIRA, Leontina. Akwe-Xerente: caminhos da (re) organização indígena. 1995. Dissertação (Mestrado) UFPB, João Pessoa, 1995.

FREIRE, José Rodrigues. Relação da conquista do gentio Xavante [1790]. Pref. de Carlos Drumond, 2. ed. São Paulo: Faculdade de Filosofia, Ciências e Letras da USP, 1951. GALLAIS, Estêvão O.P. Apóstolo do Araguaia, Frei Gil de Vilanova, missionário dominicano. Adaptação portuguesa por Frei Pedro Secondy e Soares de Azevedo. Conceição do Araguaia, Goiás, 1942.

GARCIA DA MOTTA, Diana. Relatório de viagem à área Xerente (Pis Xerente, Funil, Rio do Sono). Brasília, 10/7/1980 (Processo Funai/BSB/2297/80, Documentação Funai/ DEID), 1980. 
GOW, Peter. Of mixed blood. Kinship and History in Peruvian Amazonia. Oxford: Claredon Press, 1991.

KARASCH, Mary. Catequese e cativeiro: política indigenista em Goiás: 1780-1889. In: CARNEIRO DA CUNHA, Manuela. História dos índios no Brasil. São Paulo: Companhia das Letras, Secretaria Municipal de Cultura, Fapesp, 1992.

LOPES DA SILVA, Aracy. Dois séculos e meio de história Xavante. In: CARNEIRO DA CUNHA, Manuela. História dos índios no Brasil. São Paulo: Companhia das Letras/ Secretaria Municipal de Cultura/Fapesp, 1992.

MAGALHÃES, Basílio de. Algumas notas sobre os Cherentes. Revista do Instituto Histórico e Geográfico Brasileiro, v. 155 (1927), p. 5-30, 1928.

MATTOS, Rinaldo de. Dados informativos sobre os Xerente. 1980. Mimeografado.

MATTOS, Rinaldo de. Entrevista sobre os Xerente e a Missão Batista. Entrevista de Luís Roberto De Paula, 20, p. 1999. MAYBURY-LEWIS. David (Ed.). Dialectical societies: the Gê and Bororo of Central Brazil. Cambridge: Harvard University Press, 1979.

MAYBURY-LEWIS. David (Ed.). O selvagem e o inocente. Campinas: Ed. Unicamp, 1990.

MELATTI, Julio César. O messianismo Krahó. São Paulo: Herder, 1972.

NIMUENDAJU, Curt. Língua Šerente. Journal de la Societé des Américanistes, N.S., 21, Paris, p. 127-130, 1929.

NIMUENDAJU, Curt. The Śerente (transl. by Robert H. Lowie). Los Angeles: Southwest Museum (Frederick Webb Hodge Anniversary Publication, v. IV). 1942 (tradução livre).

NiMUENDAJU, Curt. Cartas do Sertão de Curt Nimuendaju para Carlos Estevão de Oliveira. Apresentação e notas de Tekla Hartmann. Lisboa: Museu Nacional de Etnologia Assírio \& Alvim, 2000.

OLIVEIRA, José Feliciano de. Apontamentos sobre os índios Cherentes. O Estado de São Paulo (publicado em forma de cartas; impresso nos EUA, 1897, ed. Horacio Lane), 1915.
OLIVEIRA, José Feliciano de. Os Cherente (aborígenes do Brazil Central). Revista do Instituto Histórico e Geographico de São Paulo, v. 20, p. 11-25, 1896.

OPAN, GERA/UFMT, INVESTCO. Diagnóstico etnoambiental das terras indígenas Xerente e Funil - Relatório final. Cuiabá, 2000.

POHL, Johann Emanuel. Viagem no interior do Brasil. Rio de Janeiro: Ministério da Educação e Saúde, INL, 1951, $2^{a}$ parte.

RAVAGNANI, Oswaldo Martins. A experiência Xavante com o mundo dos brancos. Araraquara: Unesp, 1991.

RIBEIRO, Darcy. Os índios e a civilização. Petrópolis: Vozes, 1982.

SAHLINS, Marshall. Homem pobre, homem rico, grande-homem, chefe: tipos políticos na Melanésia e na Polinésia (1963). In: Cultura na prática. Rio de Janeiro: Ed. da UFRJ, 2004.

SCHROEDER, Ivo. Política e parentesco nos Xerente. 2006. Tese (Doutorado em Antropologia) - Universidade de São Paulo, São Paulo, 2006.

SILVA E SOUZA, Luiz Antonio da. Memoria sobre o descobrimento, governo, população e cousas mais notaveis da Capitania de Goyaz. Revista do Instituto Histórico e Geográfico Brasileiro, v. 12, p. 429-510, 1849.

TAGGIA, Rafael de. Mappas dos indios Cherentes e Chavantes na nova povoação de Thereza Christina no rio Tocantins e dos indios Charaós da aldêa de Pedro Affonso nas margens do mesmo rio, ao norte da provincia de Goyaz. Revista do Instituto Histórico e Geográfico Brasileiro, v. 19, n. 21, Rio de Janeiro, 1898.

VIANNA, Urbino. Akuen ou Xerente. Revista do Instituto Histórico e Geográfico Brasileiro, Prefácio de Basílio de Magalhães, tomo 101, v. 155 (1927), p. 33-48, 1928.

WAIKARNÃSE XERENTE, Paulo; MATTOS, Rinaldo de. O sistema político xerente. Datilo. 21 p., 1999.

WELLS, James W. Three thousand miles through Brazil: from Rio de Janeiro to Maranhão. London: Sampson Low, Marston, Searle, \& Rivington, 1886. 


\title{
The Xerente: structure, history and politics
}

\begin{abstract}
The field of the politics among Xerente dialogues with their social structure and here it is approached starting from their space distribution in dozens of relatively autonomous settlements. The foundation of settlements replicates and strengthens a social structure that operates by opposition between sides or groups. A society so fragmented, however, is capable of concerted action in the defense of collective interests. Unless in these fleeting events, however, the interests of the groups are heeded and the political representation is suspicious. The social memory, replete by the histories of the bad choice, when they had throw away the goods of the whites, one see mobilized for an approach of the public policy and in the way of doing politics of the whites, where again they appear in groups, because this is the own form of being Akwẽ Ktabi.
\end{abstract}

Key words: Xerente Indians; history and social memory; Theresa Chistina Village; dualistic societies; social structure and indigenous politics.

\section{Los Xerente: estructura, memoria y politica}

\section{Resumen}

El campo de la política entre los Xerente dialoga con su estructura social, y aquí se le enfoca a partir de su distribución espacial en decenas de aldeas relativamente autónomas. La fundación de las aldeas replica y fortalece una estructura social que actúa mediante oposiciones entre lados o agrupamientos. Una sociedad fragmentada de esta manera, a pesar de todo, es capaz de acciones organizadas para la defensa de ios intereses colectivos. A no ser en acontecimientos fugaces, los intereses de los agrupamientos acaban por imponerse, y la representación política se pone en entredicho. La memoria social, repleta de historias de elecciones mal hechas, cuando despreciaron las cosas de los blancos, se dirige hacia una aproximación a las políticas públicas y a la manera de hacer política de los blancos, en la que de nuevo ellos se presentan en agrupamientos, ya que ésta es la forma propia de ser Akwẽ Ktabi.

Palabras-clave: indios Xerente; historia y memoria social; Aldeamiento Theresa Christina; sociedades dualistas; estructura social y política indígena.

Data de recebimento do artigo: 25/1/2010

Data de aprovação do artigo: 5/5/2010 